\title{
Anticancer Activities of Citrus Peel Polymethoxyflavones Related to Angiogenesis and Others
}

\author{
Liwen Wang, ${ }^{1}$ Jinhan Wang, ${ }^{1,2}$ Lianying Fang, ${ }^{1}$ Zuliang Zheng, ${ }^{1}$ Dexian Zhi, \\ Suying Wang, ${ }^{1}$ Shiming $\mathrm{Li}^{3}{ }^{3,4}$ Chi-Tang $\mathrm{Ho}^{,}{ }^{4}$ and Hui Zhao ${ }^{1,5}$ \\ ${ }^{1}$ Tianjin Key Laboratory of Food and Biotechnology, School of Biotechnology and Food Science, Tianjin University of Commerce, \\ Tianjin 300134, China \\ ${ }^{2}$ Institute of Radiation Medicine, Chinese Academy of Medical Sciences and Peking Union Medical College, Tianjin 300192, China \\ ${ }^{3}$ Hubei Key Laboratory of Economic Forest Germplasm Improvement and Resources Comprehensive Utilization, \\ Huanggang Normal University, Huanggang, Hubei 438000, China \\ ${ }^{4}$ Department of Food Science, Rutgers University, New Brunswick, NJ 08901-8502, USA \\ ${ }^{5}$ Department of Hematology and Translation Medicine Centre, Hebei Union University Affiliated Hospital, Tangshan, \\ Hebei 063000, China
}

Correspondence should be addressed to Hui Zhao; zhaohui@tjcu.edu.cn

Received 5 July 2014; Accepted 28 July 2014; Published 28 August 2014

Academic Editor: Zongjin Li

Copyright (C) 2014 Liwen Wang et al. This is an open access article distributed under the Creative Commons Attribution License, which permits unrestricted use, distribution, and reproduction in any medium, provided the original work is properly cited.

\begin{abstract}
Citrus is a kind of common fruit and contains multiple beneficial nutrients for human beings. Flavonoids, as a class of plant secondary metabolites, exist in citrus fruits abundantly. Due to their broad range of pharmacological properties, citrus flavonoids have gained increased attention. Accumulative in vitro and in vivo studies indicate protective effects of polymethoxyflavones (PMFs) against the occurrence of cancer. PMFs inhibit carcinogenesis by mechanisms like blocking the metastasis cascade, inhibition of cancer cell mobility in circulatory systems, proapoptosis, and antiangiogenesis. This review systematically summarized anticarcinogenic effect of citrus flavonoids in cancer therapy, together with the underlying important molecular mechanisms, in purpose of further exploring more effective use of citrus peel flavonoids.
\end{abstract}

\section{Introduction}

In our daily diet, the average intake of flavonoids of every day ranges from $150 \mathrm{mg}$ to $300 \mathrm{mg}$ [1]. As the primary source, flavonoids from citrus fruit or juice take up to $10 \%$, of which juices and fruits offer $8 \mathrm{mg}$ and $3 \mathrm{mg}$, respectively [2]. The main components in citrus possess phenols, amino acids, essential oils, pectin, carotenoids, flavonoids, and vitamin C. Although flavonoids are generally considered to be nonnutritive agents, interest in flavonoids has arisen because of their potential role in the prevention of major chronic diseases. Flavonoids are polyphenolic compounds and include a phenyl benzopyrone structure, representing as two benzene rings (C6) joined by a linear three-carbon chain (C3), with a carbonyl group at the $\mathrm{C}_{4}$ position. The citrus flavonoids include a class of glycosides, namely, hesperidin and naringin, and another class of O-methylated aglycones of flavones such as nobiletin and tangeretin, which are relatively common two polymethoxylated flavones (PMFs) [3]. PMFs exist almost ubiquitously in citrus plants. Six PMFs and three major 5demethoxyflavones can be extracted from a variety of citrus peels. The wide biochemical functions of flavonoids in orange peel have been studied extensively recently. They increased serum antioxidant capacity against lipid peroxidation [4] and reduced the elderly oxidative stress. These compounds also performed beneficial effects of anti-inflammation, antitumor $[5,6]$, and antiatherosclerosis [7]. Meanwhile, they serve as supplementary of drug chemotherapy [8], diabetes health food [9], and neuroprotective drug [10].

In recent years, epidemiological studies have shown that there is a connection that flavonoid intake may reduce the risk of developing colon cancer $[11,12]$. Moreover, it may prevent 
men against Parkinson's disease (PD) after identifying 805 participants (438 men and 367 women) who developed PD during 20-22 years of follow-up [13], help women get out of the risk of gastric cancer and breast cancer with $10 \%$ reduction in risk of breast cancer associated with high intake of citrus fruits [14], and reduce the possibility of ischemic stroke during 14 years of follow-up, confirmed with 1803 incident strokes. After adjusting for potential confounders, women in the highest compared with the lowest quintile of flavanone intake had a relative risk of ischemic stroke of 0.81 [15].

Cancer is the life threatening and dreadful disease characterized by the abnormal proliferation of cells that invade the adjacent tissues and cause the destruction of these tissues. It is the second leading cause of death all over the world. More than six million deaths each year occurring in the world are due to cancer. Several lines of evidence indicated that tumorigenesis in humans is a multistep process and these steps reflect genetic alterations that drive the progressive transformation of normal human cells into highly malignant derivatives [16]. Conventional treatment chemotherapy could cause adverse and toxic side effects on normal cells while curing cancer and therefore fails to control the disease. The alternative solution for the harmful effects of synthetic agents is the use of natural plants, which provide outstanding contribution to modern therapeutics [17]. It has been shown by clinical studies and phytochemical investigation currently that many herbs exhibit antitumor potential. In this review, we center on the latest research progress on the antitumor activities of citrus peel compounds.

\section{Anticarcinogenic Properties}

In the tumor microenvironment, from cancer cells initiation to promotion and eventually progression, compelling evidence indicates the potential activities of flavonoids in citrus peel cover inhibiting oncogenesis, proliferation, neovascularization, and metastasis and inducing apoptosis. Figure 1 schematizes the main anticarcinogenic pathways of citrus peels flavonoids and different bioactivity aspects of specific compounds stated in this review are summarized in Table 1.

2.1. Cell Cycle Arrest. Cell cycle abnormalities are closely associated with cancer, and citrus peel flavonoids substantially influence on cell cycle arrest. Cell cycle is an important regulatory mechanism of cell growth, development, and differentiation. In mammals, the cell cycle comprises the G1, S, G2, and M phases. Cell cycle checkpoints keep the maintenance of genomic integrity by inhibiting damaged or incomplete DNA. G2/M checkpoint ensures that the cells do not initiate mitosis before repairing damaged DNA after replication. The cell cycle progression depends on a cascade of enzymes by sequential activation and inactivation of cyclin, cyclin-dependent kinases (CDKs), and cyclin-dependent kinase inhibitors (CDKIs) [18]. Cdc2 interacts with cyclin $\mathrm{B} 1$ and forms a cdc2-cyclin complex. The G2/M transition is regulated by the sequential activation and inactivation of the cdc2/cyclin B complex [19]. Non-small-cell lung cancer
(NSCLC) A549 cells arrest and apoptosis can be induced by flavonoids extracted from Korean Citrus aurantium L. [20]. Downregulation of $\operatorname{cdc} 2, \operatorname{cdc} 25 \mathrm{c}$, and cyclin B1 and the upregulation of $\mathrm{p} 21$ resulted in G2/M arrest in A549 cell line. Actually, the mechanisms of parts of flavonoids components are being further explained. As one of the most prevalent flavonoids extracted from orange, hesperetin repressed CDK2, CDK4, and cyclin D and simultaneously enhanced p21 and p27 expression to block cell cycle in G1 phase [21]. It is also reported that hesperetin and naringenin exhibited the same results in cervical cancer cell $\mathrm{SiHa}$ and liver cancer cell HepG2, respectively [22, 23]. In human breast and colon cancer cells, both tangeretin and nobiletin inhibited the proliferation and led to accumulation of cells in the G1/S cell cycle compartment and did not involve induction of cell death or apoptosis. This finding may provide advantageous theory basis in treating tumors as it would restrict proliferation in a manner less likely to induce cytotoxicity and death in normal tissues [24]. More recently, the study on derivatives of citrus peel flavonoids causes widely concern as well. For instance, in all three NSCLC cells A549, H460, and H1299, 5-demethyltangeretin mediated G2/M cell cycle arrest by upregulating p53 and p21 $1^{\text {Cip1/Waf1 }}$ and downregulating cdc2 and cyclin B1 [25]. Among three 5-hydroxy polymethoxyflavones (5OH-PMFs), 5-hydroxy-3,6,7,8,3', $4^{\prime}$-hexamethoxyflavone (5HHMF), 5hydroxy-6,7,8,3', $4^{\prime}$-pentamethoxyflavone (5HPMF), and 5hydroxy-6,7,8,3', $4^{\prime}$-pentamethoxyflavone (5HTMF), the data showed that the 5HTMF-induced G0/G1 arrest was the most responsive to the change of the $\mathrm{p} 21$ and $\mathrm{p} 53$ status of the colon cancer cells, indicating the essential role of the $4^{\prime}$-methoxyl group on B ring of 5HTMF in inducing cell cycle arrest [26]. The chemical structures of flavonoids in citrus peel can be found in Figure 2. Results above inevitably support the idea that specific structural elements of the flavonoids are the key determinants of pharmacological activities.

2.2. Suppression of Proliferation and Proapoptosis. One of the most basic features of cancer cells is their ability to proliferate chronically. Apart from blocking cell cycle, flavonoids in citrus peel can also inhibit cell proliferation and promote apoptosis, especially in triple-negative (ER-/PR-/HER2-) breast cancer (TNBC). PMFs triggered influx of $\mathrm{Ca}^{2+}$ and mobilization of intracellular $\mathrm{Ca}^{2+}$ store, accompanied by activation of calpain and caspase-12 [27]. There are further researches on mechanisms of these functions. Crude methanol extracts of the peels of Citrus aurantium L. induced caspase-dependent apoptosis through Akt pathway by inhibiting expression of XIAP and Bcl-2 which are antiapoptotic proteins, providing the fact that they have anticarcinogenic activity on human leukemia cells U937 [28]. In another leukemia cell line NALM-6, hesperidin, as the glycoside of hesperetin, promoted apoptosis via conducting the expression of p53 and peroxisome proliferator-activated receptor gamma (PPAR $\gamma)$ and suppressing the activation of NF- $\kappa \mathrm{B}$ [29]. Tangeretininduced caspase- 3 activation and elevated surface phosphatidylserine exposure demonstrated tangeretin apoptosisinducing activity in LoVo/Dx cells, which might also enhance 


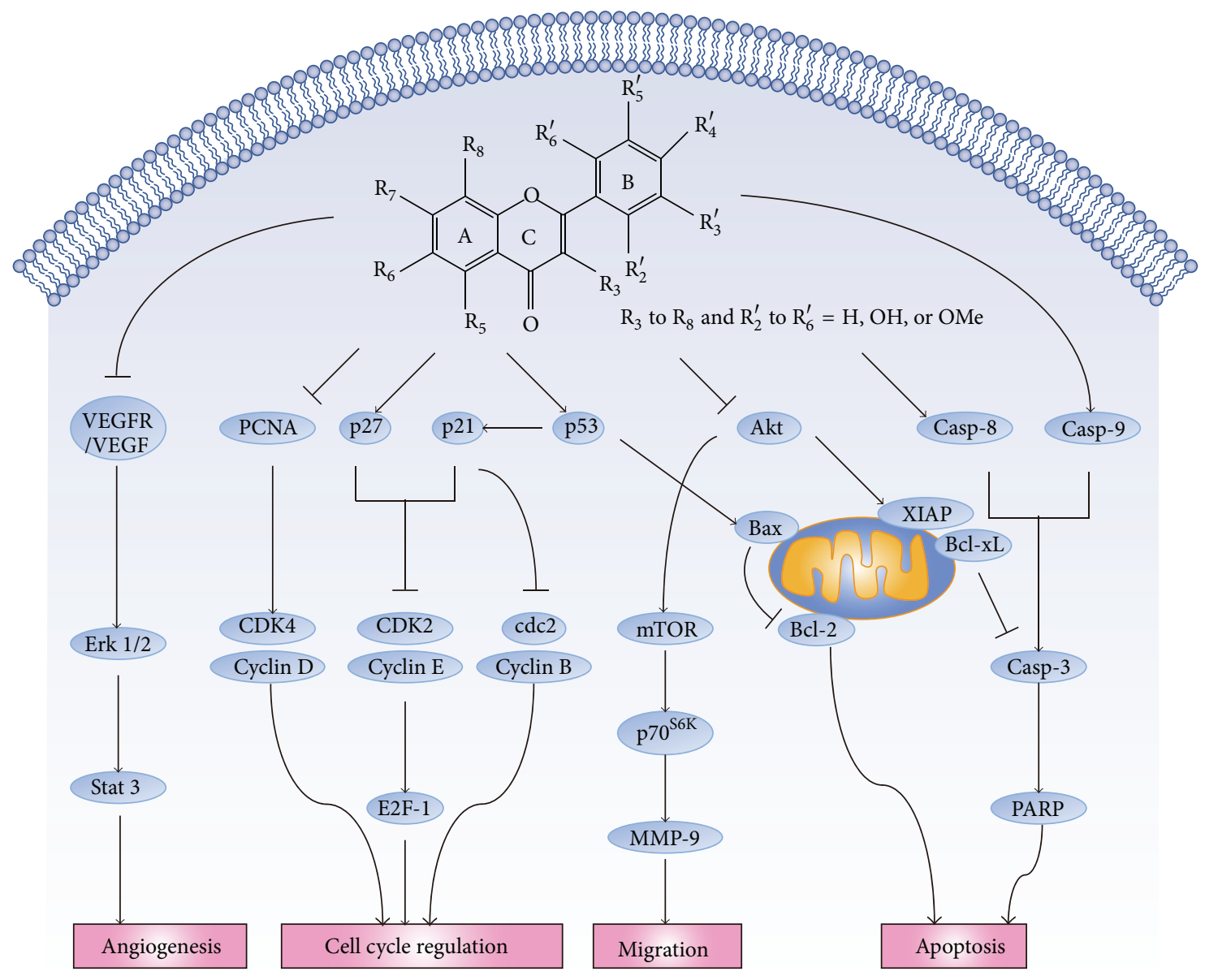

Figure 1: Polymethoxyflavones exert beneficial effects through antigrowth, antiangiogenesis and cell cycle arrest commands or mediate signals to live or die by apoptosis. At one level, this depiction is simplistic, as different cancer cells are exposed to a specific complex microenvironment, each of these pathways regulated by PMFs is connected with signals originating from other cells in the tumor microenvironment. Schematic representation of the main molecular mechanisms of flavonoids in citrus peel on anticancer.

multidrug-resistance [30]. In HCT116 human colon cancer cells, 5-hydroxy polymethoxyflavones (5OH-PMFs), especially 5HHMF and 5HTMF, induce cellular apoptosis in human colon cancer cells by p53- and Bax-dependent mechanisms [26]. Noteworthy, by looking for relationships between chemical profiles and cell viability profiles, cytotoxic effects as indicated by a decrease of $\mathrm{IC}_{50}$ values with increasing concentration of OH-PMFs were observed in different orange peel extracts [31]. Subsequent data showed that when MCF-7 breast cancer cells were treated with PMF and hydroxylated PMF separately, effective concentrations of hydroxylated PMFs in inhibiting growth, inducing apoptosis, and increasing intracellular $\mathrm{Ca}^{2+}$ were lower than those of nonhydroxylated PMFs [32]. These already available results may offer a conclusion that OH-PMFs have better potential cytotoxic effect.

In the research of mice, oral feeding of gold lotion (GL), a formulated product made from the peels of six citrus fruits, decreased the number of aberrant crypt foci (ACF) in mice colonic tissues [33]. This compound is rich in flavonoids with a total measured content of at least $450 \mathrm{ppm}$ or $0.45 \mathrm{mg} / \mathrm{mL}$; its PMFs content is as high as $106 \mathrm{ppm}$ or $0.1 \mathrm{mg} / \mathrm{mL}$. Due to its high content of flavonoids, it has also been proven to inhibit the nuclear translocation of NF- $\kappa$ B into the nucleus [34]. Similarly, hesperetin has potential effect on proliferation of cancer cell in vivo. For 1,2-dimethylhydrazine- (DMH-) induced colon cancer model in rats, it exerted significant inhibitory effect on proliferating cell nuclear antigen in ACF [35]. Moreover, hesperetin inhibited growth of aromataseexpressing MCF-7 tumor in ovariectomized athymic mice by reducing cyclin $\mathrm{D} 1, \mathrm{CDK} 4$, and $\mathrm{Bcl}-\mathrm{x}(\mathrm{L})$, while upregulating the level of $\mathrm{p} 57^{\mathrm{Kip} 2}$ [36]. Data above provided supporting evidence that flavonoids from citrus peel could suppress carcinogenesis in vivo.

Our latest research showed that, in MCF-7 human breast cancer cells, 5-acetyl-6,7,8, $4^{\prime}$-tetramethylnortangeretin (5ATAN), which replaces the methyl groups of tangeretin with acetyl groups at the C5 position of tangeretin, showed more powerful abilities than its parent compound. Then, we looked for evidence of 5-ATAN on apoptosis. Translocation of apoptosis-inducing factor (AIF) and phosphorylation of H2AX are commonly used for evaluating the impact of 
TABLE 1: Anticarcinogenic activity of citrus polymethoxyflavonoids and their derivatives.

\begin{tabular}{|c|c|c|c|}
\hline Polymethoxyflavone & Functions & Mechanisms & References \\
\hline \multirow[t]{2}{*}{ Naringin } & Cell cycle arrest & $\begin{array}{l}\text { G1 cycle arrest by increasing p } 21 \text { and decreasing survivin in } \\
\text { MDA-MB-231 xenograft mice }\end{array}$ & {$[25]$} \\
\hline & Anticancer metastasis & $\begin{array}{l}\text { Suppressed the upregulation of metallopeptidase-9 (MMP-9) and } \\
\text { repressed the PI3K/AKT/mTOR/p70S6K signaling pathway }\end{array}$ & {$[36]$} \\
\hline \multirow{4}{*}{ Hesperetin } & Cell cycle arrest & $\begin{array}{l}\text { G1-phase cell cycle arrest in human breast cancer MCF-7 cells by } \\
\text { downregulating CDK2 and CDK4 together with cyclin D and } \\
\text { upregulating p } 21^{\mathrm{Cip1}} \text { and p } 27^{\mathrm{Kip1}}\end{array}$ & [19] \\
\hline & \multirow{3}{*}{ Suppress proliferation } & $\begin{array}{l}\text { Induced the G2/M phase and increased expression of caspase- } 3 \text {, } \\
\text { caspase-8, caspase- } 9 \text {, p53, Bax, and Fas death receptor and its adaptor } \\
\text { protein Fas-associated death domain-containing protein (FADD) in } \\
\text { human cervical cancer SiHa cells }\end{array}$ & {$[20]$} \\
\hline & & $\begin{array}{l}\text { Exerted significant inhibitory effect on proliferating cell nuclear antigen } \\
\text { in ACF in 1,2-dimethylhydrazine induced colon cancer model in rats }\end{array}$ & {$[33]$} \\
\hline & & $\begin{array}{l}\text { Inhibited growth of aromatase-expressing MCF-7 tumor in } \\
\text { ovariectomized athymic mice by reducing cyclin D1, CDK4, and } \\
\text { Bcl-x }(\mathrm{L}) \text {, while upregulating the level of p57 } 7^{\mathrm{Kip} 2}\end{array}$ & {$[34]$} \\
\hline \multirow{2}{*}{ Nobiletin } & Cell cycle arrest & $\begin{array}{l}\text { Blocked cell cycle progression at G1 breast cancer cell lines } \\
\text { MDA-MB- } 435 \text { and MCF-7 and human colon cancer line HT-29 }\end{array}$ & {$[22]$} \\
\hline & Antiangiogenesis & $\begin{array}{l}\text { Inhibited angiogenic differentiation induced by VEGF and FGF by } \\
\text { downregulation of ERK1/2 and c-JNK and activation of the caspase } \\
\text { pathway }\end{array}$ & {$[42,44]$} \\
\hline \multirow{4}{*}{ Tangeretin } & Cell cycle arrest & $\begin{array}{l}\text { Blocked cell cycle progression at G1 breast cancer cell lines } \\
\text { MDA-MB- } 435 \text { and MCF-7 and human colon cancer line HT-29 }\end{array}$ & {$[22]$} \\
\hline & Suppress proliferation & $\begin{array}{l}\text { Led to caspase- } 3 \text { activation and elevated surface phosphatidylserine in } \\
\text { human cocon LoVo/Dx cells }\end{array}$ & {$[28]$} \\
\hline & Anticancer metastasis & $\begin{array}{l}\text { Inhibited PGDF-BB-induced proliferation and migration of aortic } \\
\text { smooth muscle cells by blocking AKT activation }\end{array}$ & {$[38]$} \\
\hline & Scavenging of ROS & $\begin{array}{l}\text { Inhibited cancer cell proliferation by SOD, CAT, GPx, and nonenzymatic } \\
\text { antioxidants and phase II detoxification in 7,12-dimethyl } \\
\text { benz(a)anthracene induced mammary carcinoma in rats }\end{array}$ & {$[45]$} \\
\hline 5-Demethyltangeretin (5DT) & Cell cycle arrest & $\begin{array}{l}\text { Upregulated p53 and p21 }{ }^{\text {Cipl/Wafl }} \text { and downregulated cdc-2 and cyclin B1 } \\
\text { leading to G2/M cell cycle arrest }\end{array}$ & {$[23]$} \\
\hline Sinensetin & Antiangiogenesis & $\begin{array}{l}\text { Inhibited angiogenesis by inducing cell cycle arrest in the G0/G1 phase } \\
\text { in HUVEC culture; in zebrafish embryos, it downregulated the mRNA } \\
\text { expressions of angiogenesis genes } f t t 1, k d r l \text {, and } h r a s\end{array}$ & {$[43]$} \\
\hline \multirow{2}{*}{ 5HTMF } & Suppress proliferation & $\begin{array}{l}\text { Induced cellular apoptosis in human colon cancer cells by p53- and } \\
\text { Bax-dependent mechanisms in HCT116 colon cancer cells }\end{array}$ & {$[24]$} \\
\hline & Cell cycle arrest & $\begin{array}{l}\text { Induced cell cycle arrest at G0/G1 phase through a p53- and } \\
\text { p21 }\end{array}$ & {$[24]$} \\
\hline 5HPMF & Suppress proliferation & $\begin{array}{l}\text { Induced cellular apoptosis in human colon cancer cells by p53- and } \\
\text { Bax-dependent mechanisms in HCT116 colon cancer cells }\end{array}$ & {$[24]$} \\
\hline \multirow[b]{2}{*}{ 5HHMF } & Cell cycle arrest & $\begin{array}{l}\text { Induced G2/M arrest through p53- and p21-independent mechanisms in } \\
\text { HCT116 colon cancer cells }\end{array}$ & {$[24]$} \\
\hline & Suppress proliferation & $\begin{array}{l}\text { Induced cellular apoptosis in human colon cancer cells by p53- and } \\
\text { Bax-dependent mechanisms in HCT116 colon cancer cells }\end{array}$ & {$[24]$} \\
\hline \multirow{2}{*}{ Naringenin } & Cell cycle arrest & $\begin{array}{l}\text { Partly formed an accumulation of cells in the G0/G1 and G2/M phases of } \\
\text { the cell cycle in human hepatocellular carcinoma HepG2 cells }\end{array}$ & {$[21]$} \\
\hline & Anticancer metastasis & $\begin{array}{l}\text { Induced heme oxygenase-1(HO-1) expression and subsequently } \\
\text { decreased ROS generation and VSMC activation induced by TNF- } \alpha\end{array}$ & {$[37]$} \\
\hline Hesperidin & Suppress proliferation & $\begin{array}{l}\text { Promoted apoptosis via conducting the expression of p53 and PPAR } \gamma \\
\text { and suppressing the activation of NF- } \kappa \text { B in leukemia cell NALM- } 6\end{array}$ & {$[27]$} \\
\hline \multirow{2}{*}{$\begin{array}{l}\text { Flavonoids extracted from } \\
\text { Korean Citrus aurantium L. }\end{array}$} & Cell cycle arrest & $\begin{array}{l}\text { Induced non-small-cell lung cancer (NSCLC) A549 cells arrest at the } \\
\text { G2/M checkpoint }\end{array}$ & {$[18]$} \\
\hline & Suppress proliferation & $\begin{array}{l}\text { Induced caspase-dependent apoptosis through AKT pathway by } \\
\text { inhibiting expression of XIAP and Bcl-2 in human leukemia cells U937 }\end{array}$ & {$[26]$} \\
\hline
\end{tabular}


TABle 1: Continued.

\begin{tabular}{|c|c|c|c|}
\hline Polymethoxyflavone & Functions & Mechanisms & References \\
\hline \multirow{4}{*}{ Gold lotion } & Suppress proliferation & $\begin{array}{l}\text { In azoxymethane-induced aberrant crypt foci formation, it } \\
\text { downregulated the protein levels of iNOS, COX-2, ornithine } \\
\text { decarboxylase, VEGF, and matrix metallopeptidase } 9 \text { in colonic tissues } \\
\text { of mice }\end{array}$ & [31] \\
\hline & Anticancer metastasis & $\begin{array}{l}\text { Downregulated MMP- } 2 \text { and MMP-9 protein expression levels and } \\
\text { reduced tumor volumes and weights in human prostate tumor xenograft } \\
\text { mouse model }\end{array}$ & [39] \\
\hline & \multirow{2}{*}{ Antiangiogenesis } & Significantly suppressed the protein expression level of VEGF & [39] \\
\hline & & Reduced the protein levels of VEGF in AOM-induced colonic tissues & [31] \\
\hline
\end{tabular}<smiles>O=C1CC(c2ccc(O)cc2)Oc2cc(O)cc(O)c21</smiles>

Naringenin<smiles>COc1ccc(-c2cc(=O)c3c(OC)c(OC)c(OC)c(OC)c3o2)cc1</smiles>

Tangeretin<smiles>COc1ccc(-c2cc(=O)c3c(O)c(OC)c(OC)c(OC)c3o2)cc1</smiles>

5HTMF<smiles>COc1ccc(-c2cc(=O)c3c(O)cc(O)cc3o2)cc1O</smiles>

Hesperetin<smiles>COc1ccc(-c2cc(=O)c3c(O)c(OC)c(OC)c(OC)c3o2)cc1</smiles>

5-Demethyltangeretin<smiles>COc1ccc(-c2cc(=O)c3c(O)c(OC)c(OC)c(OC)c3o2)cc1OC</smiles>
5HPMF<smiles>COc1ccc(-c2cc(=O)c3c(OC)c(OC)c(OC)c(OC)c3o2)cc1OC</smiles>

Nobiletin<smiles>COc1ccc(-c2cc(=O)c3c(OC)c(OC)c(OC)cc3o2)cc1OC</smiles>

Sinensetin

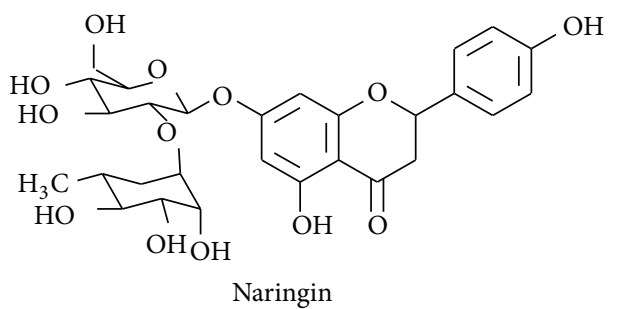

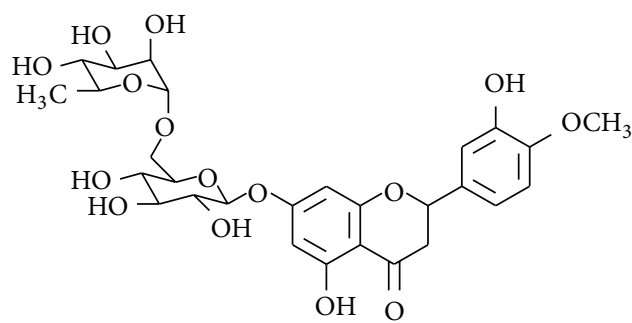

FIGURE 2: The chemical structures of citrus peel flavonoids molecules that are discussed in this paper. 
natural compounds-induced caspase-independent apoptosis pathway [37, 38]. Our results clearly supported the notion that proapoptosis of 5-ATAN acted through caspaseindependent mechanisms in case AIF translocation and H2AX phosphorylation took place in MCF-7 cells when 5ATAN was added. Allowing for apoptotic extrinsic pathway, no clear evidence had been found about activation of caspase8 , cleavage of BID, and regulation of FADD, indicating extrinsic pathway was not required under this circumstance. Strikingly, we also found that increase of $\mathrm{Bax} / \mathrm{Bcl}-2$ ratio, $\Delta \psi \mathrm{m}$ dissipation, release of cytochrome $\mathrm{C}$, and cleavage of caspase-9 after exposure to 5-ATAN in a time-dependent manner which indicated caspase-dependent intrinsic pathway were also required in the MCF-7 cells [39]. All these researches together point to a possible protective effect of citrus flavonoids and their derivatives against sustained proliferation of cancer cells.

2.3. Combined Chemotherapy. Traditional treatment of cancer has been facing a huge number of problems, in view of its complex molecular pathophysiology that varies according to each type. Several ways in the treatment of breast cancer have been developed that are surgery, chemotherapy, hormonal therapy, and radiation. Doxorubicin, a chemotherapeutic agent commonly used in breast cancer treatment, showed low effectivity, rendering its resistance and toxicity on normal tissues [40]. An approach in overcoming such problem is the development of agents used in combination with chemotherapeutic agents to lead to better result. Cochemotherapy may increase chemotherapeutic agents' efficacy, allowing the use of lower dosage of chemotherapeutic agent, resulting in the decrease of toxicity on normal tissues compared to chemotherapeutic agent alone [41]. In terms of medicine, hesperidin, tangeretin, and nobiletin could all improve doxorubicin cytotoxic chemotherapy [8]. When combining concentration of $200 \mathrm{nM}$ doxorubicin and $100 \mu \mathrm{M}$ hesperidin together in treating with MCF-7 cells, they increased cytotoxic effect, modulated cell cycle, and induced apoptosis of MCF-7 cells [42]. Meanwhile, tangeretin synergistically increased the cytotoxic effect of doxorubicin by inducing cells death and arresting cell cycle's phase both in MCF7 and T47D breast cancer cells. Different from tangeretin, nobiletin increased doxorubicin's cytotoxic activity in MCF7 cells, but not in T47D cells [8]. Cyclophosphamide is a cytotoxic alkylating drug with a high therapeutic index and is effective against a variety of cancers. Despite its effectiveness for the treatment of cancer, it induces a wide range of adverse side effects and toxicity, such as nausea, vomiting, and hematopoietic toxicity, which limit the use of this drug in clinic. In animal experiments, hesperetin can decrease the genotoxic effect of mice bone marrow cells when synergistically functioned with cyclophosphamide [43].

2.4. Anticancer Metastasis. Invasion and metastasis are a multistep process and are described as a series of discrete steps, usually called invasion-the metastatic cascade [44]. It describes a process of continuous change of cell biology, local invasion from the beginning, followed by intravasation into surrounding blood and lymphatic vessels, and transit and extravasation of cancer cells through the lymph or blood transport system and lumina vessels, then cancer nodules formation, and finally into the solid tumor growth. Metastasis of malignant tumors and proliferation of vascular smooth muscle (VSMC) are greatly related to inflammatory cell adhesion. As for matrix metallopeptidase-2 (MMP-2) and metallopeptidase-9 (MMP-9), they contribute greatly to tumor metastasis and invasion and are considered to be predictive markers for cancer. Naringin, a major flavonoid extracted from grapefruit and other citrus fruits, suppressed the upregulation of MMP-9 and repressed the $\mathrm{PI} 3 \mathrm{~K} / \mathrm{AKT} / \mathrm{mTOR}$ signaling pathway. Furthermore, naringin suppressed TNF-a-mediated release of interleukin- 6 and interleukin-8 (IL-6 and IL-8) [45]. AKT, a serine/threonine protein kinase, is a downstream target of $\mathrm{PI} 3 \mathrm{~K}$ and it plays a pivotal role in cell migration, growth, and antiapoptotic events in various types of cells [46]. Tangeretin inhibited platelet-derived growth factor- (PGDF-) BB-induced proliferation and migration of aortic smooth muscle cells by blocking AKT activation in a dose-dependent manner [47]. As the aglycone moiety of naringin chemical structure, naringenin, induced heme oxygenase-1 (HO-1) expression and subsequently decreased ROS generation and VSMC activation induced by TNF- $\alpha$ [48]. Besides, in human prostate tumor xenograft mouse model, intraperitoneal injection or oral administration GL can downregulate MMP-2 and MMP-9 protein expression levels and dramatically reduce both the weights (57\%-100\% inhibition) and volumes (78\%-94\% inhibition) of the tumors without any observed toxicity in the meantime [49].

2.5. Antiangiogenesis. Angiogenesis is a physiological process of forming new blood vessels from preexisting vessels, which involves the induction of new sprouts, coordinated and directed endothelial cell migration, proliferation, sprout fusion, and lumen formation [50]. Similar to normal tissue, tumors need supplies like nutrients and oxygen. They also need to remove metabolic waste. Tumor-associated neovasculature delivers these needs. In fact, angiogenesis is essentially required at almost every step of tumor progression and metastasis. In some physiological processes such as wound repair, angiogenesis starts only in the adult temporarily. Oppositely, in tumor growth, angiogenic switch is almost always activated and continuing to generate new blood vessels, which in turn support the tumor growth [51]. Tumor angiogenesis is a complex process and involves the crosstalk of tumor cells, endothelial cells, phagocytes, and their secreted factors, which may act as promoters or inhibitors of angiogenesis [52]. So, a balance between proangiogenic and antiangiogenic growth factors and cytokines tightly controls angiogenesis.

As one of the angiogenesis inducers, vascular endothelial growth factor-A (VEGF) can be used as a marker of angiogenesis. VEGF-A gene encodes the ligand involved in neovascularization during the embryonic and neonatal development, homeostasis, and survival of endothelial cells, as well as physiological and pathological state of adult [50]. 
When mice with human prostate tumor xenograft were intraperitoneally injected with GL, the protein expression level of VEGF was suppressed significantly [49]. In addition, oral administration of GL strongly and dose dependently reduced the protein levels of VEGF in AOM-induced colonic tissues. GL suppressing the ACF formation might be through inhibiting the colonic mucosa cellular proliferation and angiogenesis [33].

Through combined inhibition of multiple angiogenesisrelated endothelial cells (EC) functions, nobiletin had been demonstrated to have concentration-dependent inhibitory effects on angiogenic differentiation induced by VEGF and FGF (fibroblast growth factors). In a chick embryo chorioallantoic membrane assay, nobiletin showed an antiangiogenic activity with the $\mathrm{ID}_{50}$ value being $10 \mathrm{lg}(24.9 \mathrm{nmol})$ per egg [53].

With human umbilical vein endothelial cells (HUVECs) in vitro and zebrafish in vivo models, PMFs showed different degrees of potency of antiangiogenesis activity. Sinensetin, which showed the most potent antiangiogenesis activity and the lowest toxicity, inhibited angiogenesis by inducing cell cycle arrest in the G0/G1 phase in HUVEC culture and downregulating the mRNA expressions of angiogenesis genes $f l t 1, k d r l$, and hras in zebrafish [54]. Nobiletin differs from sinensetin by having methylation at the C8 position. Together with previous research of nobiletin [55], structureactivity relationship analysis indicated that the absence of a methoxylated group at the C8 position offers lower lethal toxicity in addition to enhancing the antiangiogenesis activity via observing intersegmental vessel development in zebrafish embryos [54].

2.6. Scavenging of ROS. Flavonoids also exert their chemopreventative effect via inhibition of certain phase I metabolizing enzymes, such as cytochrome P450 which metabolically activates a large number of procarcinogens triggering carcinogenesis. The chemopreventative effects of flavonoids are closely linked to their anticancer properties that involve the scavenging of reactive oxygen species (ROS) and growth promoting oxidants which are the major catalysts for tumor promotion. Tangeretin, a polymethoxylated flavone, can inhibit cancer cell proliferation by improving antioxidant properties such as decreasing the levels of lipid peroxide, enzymatic antioxidants SOD, CAT, and GPx, and nonenzymatic antioxidants such as GSH, vitamin C, and vitamin $\mathrm{E}$ in 7,12-dimethyl benz(a)anthracene (DMBA) induced mammary carcinoma in rats [56]. Otherwise, the propensity of a flavonoid to inhibit free radical mediated events is governed by its chemical structure. Specific structural elements of the flavonoids determinate antioxidation activity of these compounds. Free radical scavenging capacity is primarily attributed to the high reactivity of hydroxyl substituents. Flavonols and flavanols with a 3-OH group both have planarity, which increased flavonoid phenoxyl radical stability correspondingly [57]. Furthermore, methoxy groups introduce unfavorable steric effects and increase lipophilicity and membrane partitioning. A double bond and carbonyl function in the heterocycle or polymerization of the nuclear structure increased activity by affording a more stable flavonoid radical through conjugation and electron delocalization [58]. Remarkably, glycosylation of flavonoids reduced their in vitro antioxidantive activity compared to the corresponding aglycones [59]. The same results were observed in O-methylated flavonoids, which showed weaker antioxidation than their respective aglycones [60]. As an example, 5,3-didemethylnobiletin showed much stronger inhibitory effect on human colon cancer cell growth than 5-demethylnobiletin by cell viability assay [61]. These correlations between the flavonoid structure and their free radical scavenging activity need to be further investigated for better understanding and clinical application.

\section{Pharmacokinetics of PMFs and Cancer Therapy}

Pharmacokinetics describes how the body affects a specific drug after administration through mechanisms of absorption and distribution, as well as the chemical changes of the substance in the body. At a practical level, a drug's bioavailability can be defined as the proportion of the drug that reaches its site of action. Poor absorption and extensive conjugative metabolisms greatly limit bioavailability of dietary flavonoids.

3.1. PMF's Bioavailability. The bioavailability is an overall effect of absorption, distribution, metabolism, and excretion and plays an important role in dictating cancer preventive efficacy of dietary components in humans. Bioavailability testing can be divided into in vitro and in vivo bioavailability. In vitro bioavailability test can be a good predictor of the latter one.

Currently, human colon adenocarcinoma cell line caco2 cell model is established to simulate the human intestinal absorption so as to test permeability and study absorption mechanism. The caco- 2 data of $3^{\prime}$-hydroxy-5,6,7,4' -tetramethoxyflavone, 3,5,6,7,8,3',4'-heptamethoxyflavone, and 3-hydroxy-5,6,7,8, $3^{\prime}, 4^{\prime}$-hexamethoxyflavone showed superb permeability [62]. Meanwhile, the lyophilisation solubility assay (LYSA), a rapid method to test drugs and active nutrients compounds, was adapted to measure the solubility of PMFs. The solubility data showed that hydroxylated PMFs were better than their fully methoxylated counterparts. Considering the solubility and permeability together, the overall high absorption of PMFs contributes to their good bioavailability.

Also, in NSCLC A549 cell line, 5-hydroxylated PMFs had much stronger inhibitory effects on cancer cells in comparison with their permethoxylated counterparts, for $\mathrm{IC}_{50}$ value of 5-demethyltangeretin (5DT) was 78.9-fold lower than that of tangeretin. Since cancer cells can pump the cytotoxic agents out via overexpression of multidrug resistant efflux proteins, cells were treated with 5DT or tangeretin at the same concentration. HPLC analysis revealed that the intracellular levels of 5DT in NSCLC cells were 2.7-4.9fold higher than those of TAN. This suggested that NSCLC cells may have better uptake efflux of 5DT compared with TAN. Additionally, molecular structure showed that 5DT had higher lipophilicity than tangeretin [63]. High lipophilicity 
could enhance 5DT binding to the plasma membrane, which in turn could promote the uptake of 5DT into cytosol of the cancer cells.

3.2. PMFs and Metabolites in Cancer Therapy. Biotransformation of dietary components is crucial for their in vivo biological activities after oral ingestion because the process of drug metabolism notably influences drugs effects and toxicity. In the research of nobiletin metabolites, by comparing supercritical fluid chromatography (SFC) profiles of metabolite mixtures with the synthesized standard compounds, three major metabolites were proved to be $4^{\prime}$-demethylnobiletin, $3^{\prime}$-demethylnobiletin, and $3^{\prime}, 4^{\prime}$-didemethylnobilietin in mouse urine [64]. Further research had demonstrated that $3^{\prime}, 4^{\prime}$-didemethylnobilietin exhibited greater bioactivities than nobiletin. As another example, it has been confirmed that 5-demethylnobiletin had strong antiproliferative effects on cancer cells. Thus, urine samples were collected from mice fed with 5-demethylnobiletin and processed for HPLC-ESI-MS analysis. Three major metabolites were characterized as $5,3^{\prime}$-didemethylnobiletin, 5, $4^{\prime}$ didemethylnobiletin, and 5,3', $4^{\prime}$-tridemethylnobiletin. Cell viability assay in human colon cancer cells demonstrated that these three metabolites showed $\mathrm{IC}_{50}$ of $0.12,5.5$, and $4.2 \mu \mathrm{M}$ in SW620 cells, while 5-demethylnobiletin at $10 \mu \mathrm{M}$ only caused $37 \%$ inhibition [61]. Hence, it can be concluded that PMFs in citrus peels may produce much stronger active anticancer compounds through biotransformation.

\section{Conclusions}

Taken all together, a considerable number of well-established lines of evidence have confirmed that flavonoids in citrus peel exhibit a remarkable spectrum of efficacious biological activities, particularly in antitumorigenesis. Excellent permeability through membrane allows citrus flavonoids to possess great bioavailability which consequently attracts researchers to perform scientific studies for effective disease prevention and treatment. There are more modified flavonoids in citrus peel being investigated, which could offer help to improve dose-effect relationship greatly and advance the security and stability of compounds.

\section{Conflict of Interests}

The authors declare that there is no conflict of interests regarding the publication of this paper.

\section{Acknowledgments}

This study was supported by the National Natural Science Foundation of China (Grant nos. 81172837 and 31270050), the Tianjin Research Program of Application Foundation and Advanced Technology (Grant no. 13JCQNJC12200), and the Tianjin Innovative Research Team Grant of Agriculture Storage and Procession (TD-12-5049).

\section{References}

[1] M. Danihelová and E. Šturdík, "Flavonoid natural sources and their importance in the human diet," Potravinarstvo, vol. 5, no. 4, pp. 12-24, 2011.

[2] K. C. Ock, J. C. Sang, and W. O. Song, "Estimated dietary flavonoid intake and major food sources of U.S. adults," Journal of Nutrition, vol. 137, no. 5, pp. 1244-1252, 2007.

[3] S. Li, H. Wang, L. Guo, H. Zhao, and C.-T. Ho, "Chemistry and bioactivity of nobiletin and its metabolites," Journal of Functional Foods, vol. 6, pp. 2-10, 2014.

[4] J. M. Assini, E. E. Mulvihill, B. G. Sutherland et al., "Naringenin prevents cholesterol-induced systemic inflammation, metabolic dysregulation, and atherosclerosis in Ldlr/mice," Journal of Lipid Research, vol. 54, no. 3, pp. 711-724, 2013.

[5] D. F. Romagnolo and O. I. Selmin, "Flavonoids and cancer prevention: a review of the evidence," Journal of Nutrition in Gerontology and Geriatrics, vol. 31, no. 3, pp. 206-238, 2012.

[6] E. Park and J. M. Pezzuto, "Flavonoids in cancer prevention," Anti-Cancer Agents in Medicinal Chemistry, vol. 12, no. 8, pp. 836-851, 2012.

[7] E. E. Mulvihill and M. W. Huff, "Citrus flavonoids and the prevention of atherosclerosis," Cardiovascular \& Hematological Disorders-Drug Targets, vol. 12, no. 2, pp. 84-91, 2012.

[8] E. Meiyanto and A. Hermawan, "Natural products for cancertargeted therapy: citrus flavonoids as potent chemopreventive agents," Asian Pacific Journal of Cancer Prevention, vol. 13, no. 2, pp. 427-436, 2012.

[9] O. I. Aruoma, B. Landes, D. Ramful-Baboolall et al., "Functional benefits of citrus fruits in the management of diabetes," Preventive Medicine, vol. 54, pp. S12-S16, 2012.

[10] S. Hwang, P. Shih, and G. Yen, "Neuroprotective effects of citrus flavonoids," Journal of Agricultural and Food Chemistry, vol. 60, no. 4, pp. 877-885, 2012.

[11] L. Andrews, "Dietary flavonoids for the prevention of colorectal cancer," Clinical Journal of Oncology Nursing, vol. 17, no. 6, pp. 671-672, 2013.

[12] C. La Vecchia, A. Decarli, M. Serafini et al., "Dietary total antioxidant capacity and colorectal cancer: a large case-control study in Italy," International Journal of Cancer, vol. 133, no. 6, pp. 1447-1451, 2013.

[13] X. Gao, A. Cassidy, M. A. Schwarzschild, E. B. Rimm, and A. Ascherio, "Habitual intake of dietary flavonoids and risk of Parkinson disease," Neurology, vol. 78, no. 15, pp. 1138-1145, 2012.

[14] J. K. Song and J. M. Bae, "Citrus fruit intake and breast cancer risk: a quantitative systematic review," Journal of Breast Cancer, vol. 16, no. 1, pp. 72-76, 2013.

[15] A. Cassidy, E. B. Rimm, É. J. O’Reilly et al., "Dietary flavonoids and risk of stroke in women," Stroke, vol. 43, no. 4, pp. 946-951, 2012.

[16] D. Hanahan and R. A. Weinberg, "The hallmarks of cancer," Cell, vol. 100, no. 1, pp. 57-70, 2000.

[17] S. Sultana, H. M. Asif, H. M. Nazar, N. Akhtar, J. U. Rehman, and R. U. Rehman, "Medicinal plants combating against cancera green anticancer approach," Asian Pacific Journal of Cancer Prevention, vol. 15, no. 11, pp. 4385-4394, 2014.

[18] X. Grana and E. P. Reddy, "Cell cycle control in mammalian cells: Role of cyclins, cyclin dependent kinases (CDKs), growth suppressor genes and cyclin-dependent kinase inhibitors (CKIs)," Oncogene, vol. 11, no. 2, pp. 211-219, 1995. 
[19] K. Vermeulen, D. R. van Bockstaele, and Z. N. Berneman, "The cell cycle: a review of regulation, deregulation and therapeutic targets in cancer," Cell Proliferation, vol. 36, no. 3, pp. 131-149, 2003.

[20] K. I. Park, H. S. Park, A. Nagappan et al., "Induction of the cell cycle arrest and apoptosis by flavonoids isolated from Korean Citrus aurantium L. in non-small-cell lung cancer cells," Food Chemistry, vol. 135, no. 4, pp. 2728-2735, 2012.

[21] E. J. Choi, "Hesperetin induced G1-phase cell cycle arrest in human breast cancer MCF-7 cells: involvement of CDK4 and p21," Nutrition and Cancer, vol. 59, no. 1, pp. 115-119, 2007.

[22] A. A. Alshatwi, E. Ramesh, V. S. Periasamy, and P. Subash-Babu, "The apoptotic effect of hesperetin on human cervical cancer cells is mediated through cell cycle arrest, death receptor, and mitochondrial pathways," Fundamental and Clinical Pharmacology, vol. 27, no. 6, pp. 581-592, 2013.

[23] D. Arul and P. Subramanian, "Naringenin (citrus flavonone) induces growth inhibition, cell cycle arrest and apoptosis in human hepatocellular carcinoma cells," Pathology and Oncology Research, vol. 19, no. 4, pp. 763-770, 2013.

[24] K. L. Morley, P. J. Ferguson, and J. Koropatnick, "Tangeretin and nobiletin induce G1 cell cycle arrest but not apoptosis in human breast and colon cancer cells," Cancer Letters, vol. 251, no. 1, pp. 168-178, 2007.

[25] N. Charoensinphon, P. Qiu, P. Dong et al., "5-demethyltangeretin inhibits human nonsmall cell lung cancer cell growth by inducing G2/M cell cycle arrest and apoptosis," Molecular Nutrition \& Food Research, vol. 57, no. 12, pp. 2103-2111, 2013.

[26] P. Qiu, H. Guan, P. Dong et al., "The p53-, Bax- and p21dependent inhibition of colon cancer cell growth by 5-hydroxy polymethoxyflavones," Molecular Nutrition and Food Research, vol. 55, no. 4, pp. 613-622, 2011.

[27] H. Li, B. Yang, J. Huang et al., "Naringin inhibits growth potential of human triple-negative breast cancer cells by targeting $\beta$ catenin signaling pathway," Toxicology Letters, vol. 220, no. 3, pp. 219-228, 2013.

[28] M. H. Han, W. S. Lee, J. N. Lu et al., "Citrus aurantium L. exhibits apoptotic effects on U937 human leukemia cells partly through inhibition of Akt," International Journal of Oncology, vol. 40, no. 6, pp. 2090-2096, 2012.

[29] A. Ghorbani, M. Nazari, M. Jeddi-Tehrani, and H. Zand, "The citrus flavonoid hesperidin induces p53 and inhibits NF- $\kappa \mathrm{B}$ activation in order to trigger apoptosis in NALM-6 cells: involvement of PPAR $\gamma$-dependent mechanism," European Journal of Nutrition, vol. 51, no. 1, pp. 39-46, 2012.

[30] O. Wesołowska, J. Wiśniewski, K. Środa-Pomianek et al., "Multidrug resistance reversal and apoptosis induction in human colon cancer cells by some flavonoids present in citrus plants," Journal of Natural Products, vol. 75, no. 11, pp. 1896-1902, 2012.

[31] A. Gosslau, K. Y. Chen, C.-T. Ho, and S. Li, "Anti-inflammatory effects of characterized orange peel extracts enriched with bioactive polymethoxyflavones," Food Science and Human Wellness, vol. 3, no. 1, pp. 26-35, 2014.

[32] I. N. Sergeev, C. T. Ho, S. Li, J. Colby, and S. Dushenkov, "Apoptosis-inducing activity of hydroxylated polymethoxyf lavones and polymethoxyflavones from orange peel in human breast cancer cells," Molecular Nutrition and Food Research, vol. 51, no. 12, pp. 1478-1484, 2007.

[33] C. S. Lai, S. Li, C. B. Liu et al., "Effective suppression of azoxymethane-induced aberrant crypt foci formation in mice with citrus peel flavonoids," Molecular Nutrition and Food Research, vol. 57, no. 3, pp. 551-555, 2013.
[34] S. Li, Y. C. Lin, C. T. Ho et al., "Formulated extract from multiple citrus peels impairs dendritic cell functions and attenuates allergic contact hypersensitivity," International Immunopharmacology, vol. 20, no. 1, pp. 12-23, 2014.

[35] N. Nalini, S. Aranganathan, and J. Kabalimurthy, "Chemopreventive efficacy of hesperetin (citrus flavonone) against 1,2dimethylhydrazine-induced rat colon carcinogenesis," Toxicology Mechanisms and Methods, vol. 22, no. 5, pp. 397-408, 2012.

[36] L. Ye, F. L. Chan, S. Chen, and L. K. Leung, "The citrus flavonone hesperetin inhibits growth of aromatase-expressing MCF-7 tumor in ovariectomized athymic mice," Journal of Nutritional Biochemistry, vol. 23, no. 10, pp. 1230-1237, 2012.

[37] C. Candé, N. Vahsen, C. Garrido, and G. Kroemer, "Apoptosisinducing factor (AIF): caspase-independent after all," Cell Death and Differentiation, vol. 11, no. 6, pp. 591-595, 2004.

[38] C. Lu, F. Zhu, Y. Cho et al., "Cell apoptosis: requirement of $\mathrm{H} 2 \mathrm{AX}$ in DNA ladder formation, but not for the activation of caspase-3," Molecular Cell, vol. 23, no. 1, pp. 121-132, 2006.

[39] J. Wang, Y. Duan, D. Zhi et al., "Pro-apoptotic effects of the novel tangeretin derivate 5-acetyl-6,7,8,4'-tetramethylnortangeretin on MCF-7 breast cancer cells," Cell Biochemistry and Biophysics, 2014.

[40] C. Fimognari, M. Nüsse, M. Lenzi, D. Sciuscio, G. CantelliForti, and P. Hrelia, "Sulforaphane increases the efficacy of doxorubicin in mouse fibroblasts characterized by p53 mutations," Mutation Research: Fundamental and Molecular Mechanisms of Mutagenesis, vol. 601, no. 1-2, pp. 92-101, 2006.

[41] A. Bast, H. Kaiserová, G. J. den Hartog, G. R. Haenen, and W. J. F. van der Vijgh, "Protectors against doxorubicin-induced cardiotoxicity: flavonoids," Cell Biology and Toxicology, vol. 23, no. 1, pp. 39-47, 2007.

[42] A. Hermawan, "Hesperidin increase cytotoxic effect of doxorubicin in MCF-7 cells," Indonesian Journal of Pharmacy, vol. 21, no. 1, pp. 8-16, 2010.

[43] A. Ahmadi, S. J. Hosseinimehr, F. Naghshvar, E. Hajir, and M. Ghahremani, "Chemoprotective effects of hesperidin against genotoxicity induced by cyclophosphamide in mice bone marrow cells," Archives of Pharmacal Research, vol. 31, no. 6, pp. 794797, 2008.

[44] J. E. Talmadge and I. J. Fidler, "AACR centennial series: the biology of cancer metastasis: historical perspective," Cancer Research, vol. 70, no. 14, pp. 5649-5669, 2010.

[45] E. Lee, D. Kim, W. Kim, and S. Moon, "Naringin inhibits matrix metalloproteinase-9 expression and AKT phosphorylation in tumor necrosis factor- $\alpha$-induced vascular smooth muscle cells," Molecular Nutrition and Food Research, vol. 53, no. 12, pp. 15821591, 2009.

[46] E. A. Goncharova, A. J. Ammit, C. Irani et al., "PI3K is required for proliferation and migration of human pulmonary vascular smooth muscle cells," American Journal of Physiology-Lung Cellular and Molecular Physiology, vol. 283, no. 2, pp. L354L363, 2002.

[47] J. Seo, H. S. Lee, S. Ryoo, J. H. Seo, B. Min, and J. H. Lee, "Tangeretin, a citrus flavonoid, inhibits PGDF-BB-induced proliferation and migration of aortic smooth muscle cells by blocking AKT activation," European Journal of Pharmacology, vol. 673, no. 1-3, pp. 56-64, 2011.

[48] S. Chen, Y. Ding, W. Tao, W. Zhang, T. Liang, and C. Liu, "Naringenin inhibits TNF- $\alpha$ induced VSMC proliferation and migration via induction of HO-1," Food and Chemical Toxicology, vol. 50, no. 9, pp. 3025-3031, 2012. 
[49] C. Lai, S. Li, Y. Miyauchi, M. Suzawa, C. Ho, and M. Pan, "Potent anti-cancer effects of citrus peel flavonoids in human prostate xenograft tumors," Food and Function, vol. 4, no. 6, pp. 944949, 2013

[50] N. M. Pandya, N. S. Dhalla, and D. D. Santani, "Angiogenesis-a new target for future therapy," Vascular Pharmacology, vol. 44, no. 5, pp. 265-274, 2006.

[51] D. Hanahan and R. A. Weinberg, "Hallmarks of cancer: the next generation," Cell, vol. 144, no. 5, pp. 646-674, 2011.

[52] T. A. Bhat and R. P. Singh, "Tumor angiogenesis: a potential target in cancer chemoprevention," Food and Chemical Toxicology, vol. 46, no. 4, pp. 1334-1345, 2008.

[53] K. Kunimasa, M. Ikekita, M. Sato et al., "Nobiletin, a citrus polymethoxyflavonoid, suppresses multiple angiogenesisrelated endothelial cell functions and angiogenesis in vivo," Cancer Science, vol. 101, no. 11, pp. 2462-2469, 2010.

[54] I. K. Lam, D. Alex, Y. H. Wang et al., "In vitro and in vivo structure and activity relationship analysis of polymethoxylated flavonoids: identifying sinensetin as a novel antiangiogenesis agent," Molecular Nutrition and Food Research, vol. 56, no. 6, pp. 945-956, 2012.

[55] K. H. Lam, D. Alex, I. K. Lam, S. K. W. Tsui, Z. F. Yang, and S. M. Y. Lee, "Nobiletin, a polymethoxylated flavonoid from citrus, shows anti-angiogenic activity in a zebrafish in vivo model and HUVEC in vitro model," Journal of Cellular Biochemistry, vol. 112, no. 11, pp. 3313-3321, 2011.

[56] A. Lakshmi and S. Subramanian, "Chemotherapeutic effect of tangeretin, a polymethoxylated flavone studied in 7, 12dimethylbenz(a)anthracene induced mammary carcinoma in experimental rats," Biochimie, vol. 99, pp. 96-109, 2014.

[57] S. A. B. E. van Acker, M. J. de Groot, D. D. van Berg et al., "A quantum chemical explanation of the antioxidant activity of flavonoids," Chemical Research in Toxicology, vol. 9, no. 8, pp. 1305-1312, 1996.

[58] K. E. Heim, A. R. Tagliaferro, and D. J. Bobilya, "Flavonoid antioxidants: chemistry, metabolism and structure-activity relationships," Journal of Nutritional Biochemistry, vol. 13, no. 10, pp. 572-584, 2002.

[59] B. Mishra, K. I. Priyadarsini, M. S. Kumar, M. K. Unnikrishnan, and $\mathrm{H}$. Mohan, "Effect of $\mathrm{O}$-glycosilation on the antioxidant activity and free radical reactions of a plant flavonoid, chrysoeriol," Bioorganic and Medicinal Chemistry, vol. 11, no. 13, pp. 2677-2685, 2003.

[60] D. Amić and B. Lučić, "Reliability of bond dissociation enthalpy calculated by the PM6 method and experimental TEAC values in antiradical QSAR of flavonoids," Bioorganic and Medicinal Chemistry, vol. 18, no. 1, pp. 28-35, 2010.

[61] J. Zheng, M. Song, P. Dong et al., "Identification of novel bioactive metabolites of 5-demethylnobiletin in mice," Molecular Nutrition \& Food Research, vol. 57, no. 11, pp. 1999-2007, 2013.

[62] S. Li, M.-H. Pan, C.-Y. Lo et al., "Chemistry and health effects of polymethoxyflavones and hydroxylated polymethoxyflavones," Journal of Functional Foods, vol. 1, no. 1, pp. 2-12, 2009.
[63] P. Dong, P. Qiu, Y. Zhu et al., "Simultaneous determination of four 5-hydroxy polymethoxyflavones by reversed-phase high performance liquid chromatography with electrochemical detection," Journal of Chromatography A, vol. 1217, no. 5, pp. 642-647, 2010.

[64] S. Li, Z. Wang, S. Sang, M. T. Huang, and C. T. Ho, "Identification of nobiletin metabolites in mouse urine," Molecular Nutrition and Food Research, vol. 50, no. 3, pp. 291-299, 2006. 


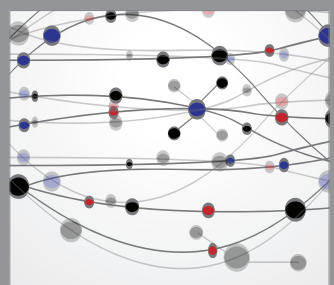

The Scientific World Journal
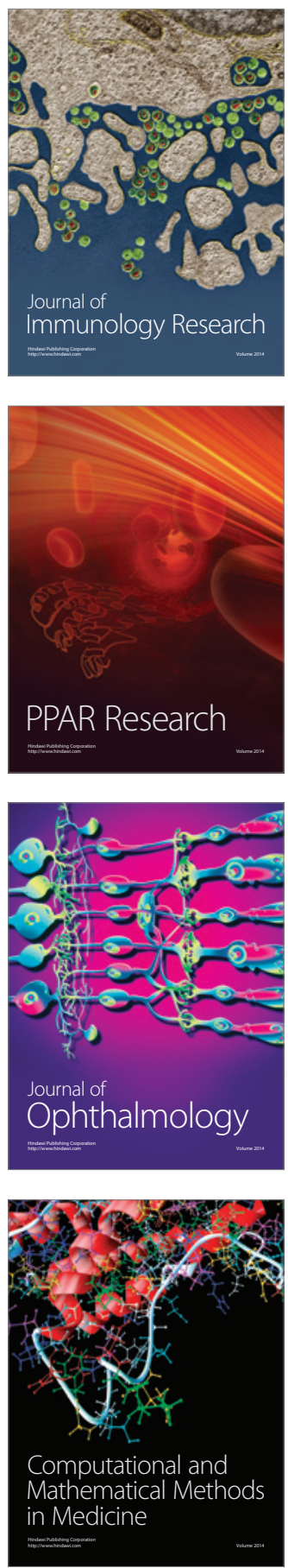

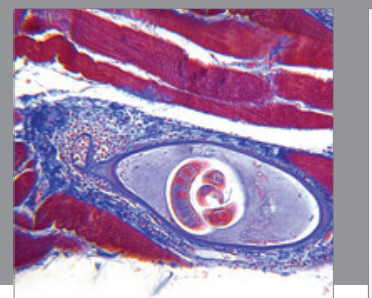

Gastroenterology

Research and Practice
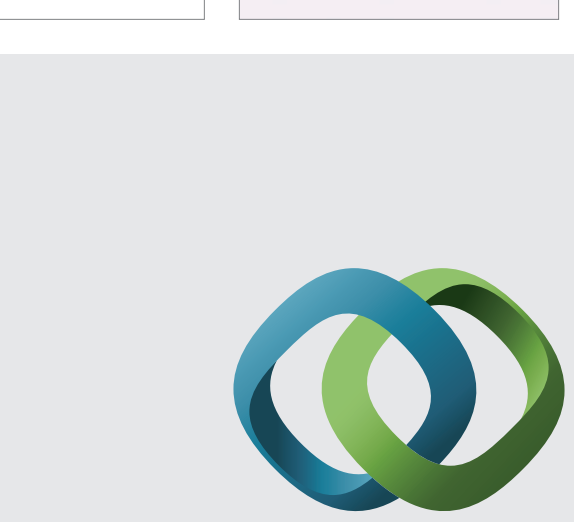

\section{Hindawi}

Submit your manuscripts at

http://www.hindawi.com
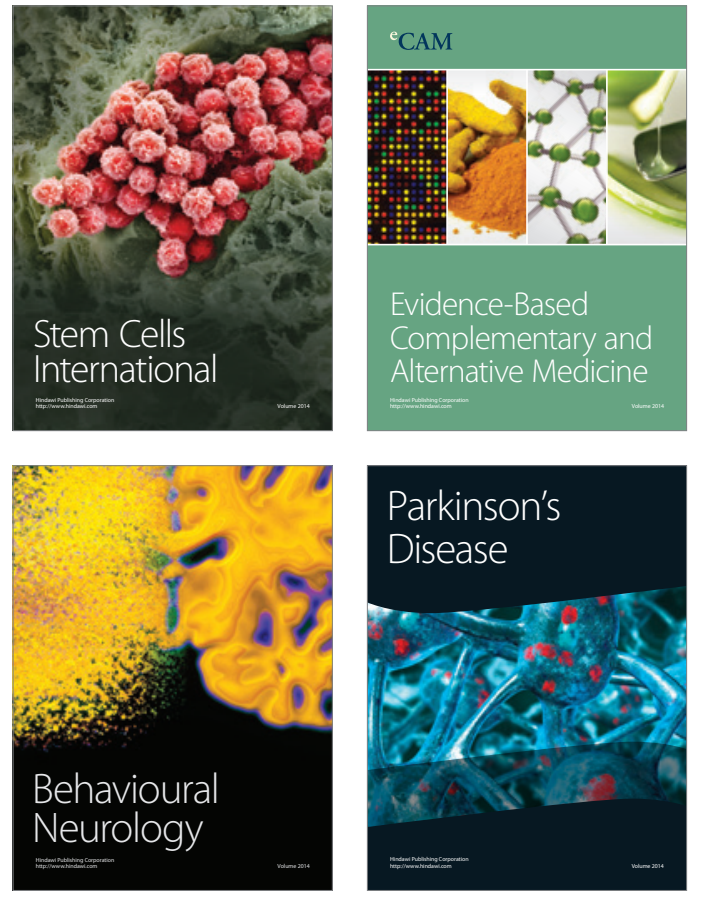
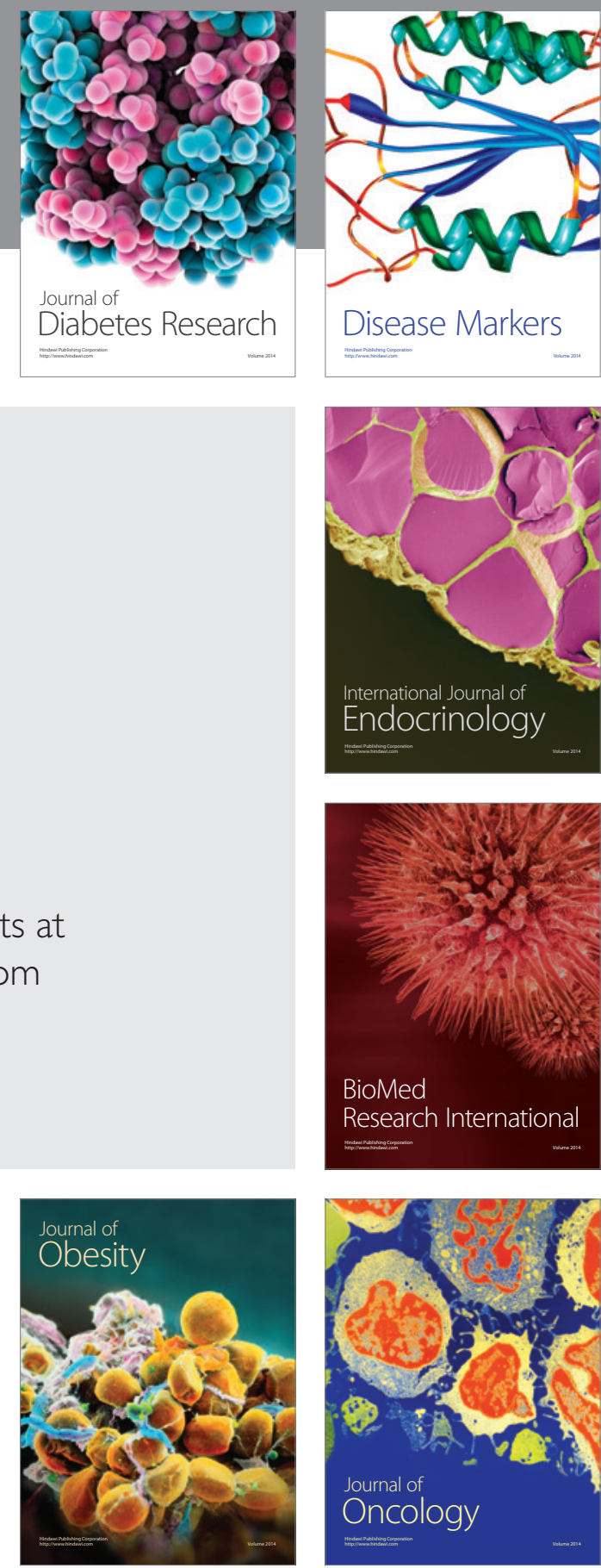

Disease Markers
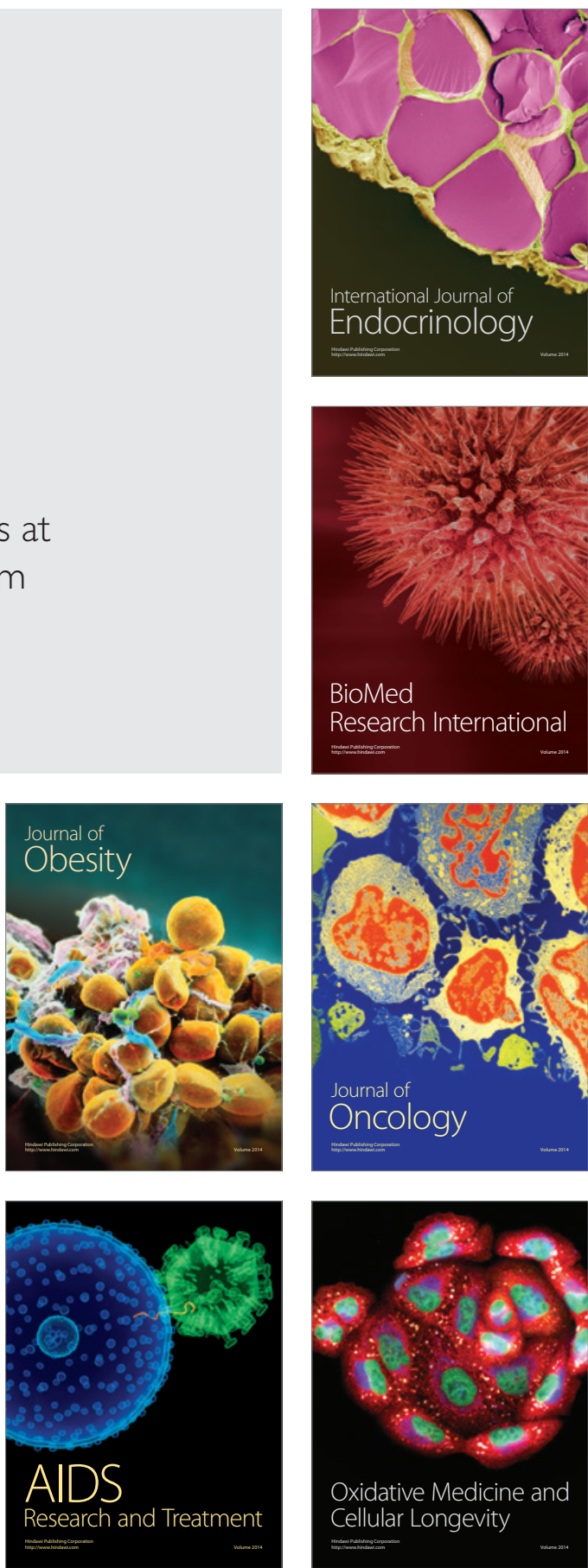